\title{
Rotavirus diarrhea disease burden in Peru: the need for a rotavirus vaccine and its potential cost savings
}

\author{
Peter Ehrenkranz, ${ }^{1}$ Claudio F. Lanata, ${ }^{2}$ Mary E. Penny, ${ }^{2}$ \\ Eduardo Salazar-Lindo, ${ }^{3}$ and Roger I. Glass ${ }^{4}$
}

ABSTRACT Objective. To assess the disease burden of rotavirus diarrhea in Peru as well the need for and the potential cost savings with a rotavirus vaccine in that country.

Methods. To assess the burden of rotavirus diarrhea in Peru, we reviewed published and unpublished reports where rotavirus was sought as the etiologic agent of diarrhea in children. Rotavirus detection rates obtained from these studies were combined with diarrhea incidence rates from a number of national surveys in order to estimate both the burden of rotavirus diarrhea in the country and its associated medical costs.

Results. Rotavirus is a significant cause of morbidity and mortality in Peruvian children. In their first 5 years of life, an estimated 1 in 1.6 children will experience an episode of rotavirus diarrhea, 1 in 9.4 will seek medical care, 1 in 19.7 will require hospitalization, and 1 in 375 will die of the disease. Per year, this represents approximately 384000 cases, 64000 clinic visits, 30000 hospitalizations, and 1600 deaths. The annual cost of medical care alone for these children is approximately US\$2.6 million-and that does not take into account the indirect or societal costs of the illness and the deaths.

Conclusions. Rotavirus immunization provides the prospect of decreasing the morbidity and mortality from diarrhea in Peru, but a vaccine regimen would have to be relatively inexpensive, a few dollars or less per child. Future cost-effectiveness analyses should explore the total costs (medical as well as indirect or societal) associated with rotavirus diarrhea. Newly licensed vaccines should be tested according to both their ability to avert deaths and their efficacy with fewer than three doses. All three of these factors could increase the cost savings associated with a rotavirus vaccine.

Key words: $\quad$ Rotavirus, immunization, diarrhea, Peru, cost-effectiveness.

Rotavirus is the major cause of severe diarrhea among children under

\footnotetext{
1 Emory University, School of Medicine, Atlanta, Georgia, United States of America.

2 Instituto de Investigación Nutricional, Lima, Perú.

3 Hospital Nacional Cayetano Heredia, Lima, Perú.

4 United States of America, Centers for Disease Control and Prevention, Viral Gastroenteritis Section, Atlanta, Georgia, United States of America. Send correspondence and reprint requests to: Roger Glass, Viral Gastroenteritis Section, MS G04, CDC, 1600 Clifton Road, NE, Atlanta, GA 30333, United States of America; telephone: 404-639-3577; fax 404-639-3645; e-mail: rig2@cdc.gov
}

5 years of age globally, causing $20 \%-$ $40 \%$ of hospitalizations for acute watery diarrhea and 418000 to 520000 deaths each year (1). Rotavirus vaccines in development will have their greatest benefit among children in developing countries, who suffer the most rotavirus-related deaths. However, with the licensing of the Wyeth Lederle RotaShield ${ }^{\circledR}$ vaccine by the United States Food and Drug Administration in August 1998, children in the
United States of America became the first target for commercial distribution of a rotavirus vaccine. These children had suffered few deaths but much rotavirus-related illness, clinic visits, and hospitalizations. In turn, their parents had experienced substantial societal costs from work days lost while caring for children with preventable diarrhea. Given the potential benefits of the rotavirus vaccine, the Advisory Committee on Immunization Practices 
of the United States and the American Academy of Pediatrics recommended the rotavirus vaccine for the routine immunization of children in the United States, to be administered orally at 2, 4, and 6 months of age as part of the routine schedule for childhood immunization $(2,3)$.

One year later, warnings about intussusception surfaced, and the manufacturer removed the vaccine from the market. Subsequent studies found rates of intussusception attributable to that vaccine of approximately 1 in 12000 children (4). The true risk remains to be determined, but given the high risk of rotavirus deaths in developing countries-estimated at 1 in 200 children under 5 years of age-if the first licensed vaccine were to become available again, it could prevent some of these deaths and provide a benefit that exceeds the risk of intussusception (5). Barring the reintroduction of RotaShield $^{\circledR}$, new vaccines that may avoid this complication altogether are currently being tested.

Reflecting these issues, a recent consensus meeting held at the World Health Organization (WHO) in Geneva recognized that a rotavirus vaccine would most directly impact children in developing countries. The meeting participants recommended that developing countries begin to review all locally available data on the epidemiology and burden of rotavirus in their own settings (6).

In Peru the Ministry of Health $(\mathrm{MOH})$ maintains an active interest in the treatment and control of diarrheal disease, especially among children. In the population younger than 5 years of age, mortality is estimated to be approximately 60 deaths per 1000 , and diarrhea is the second most common cause of death (7). Many studies have examined the etiology of diarrhea in both community and hospital settings, and Peruvian investigators have performed a number of field trials to measure the efficacy of candidate rotavirus vaccines.

To assess the burden of rotavirus diarrhea in Peru, we reviewed published and unpublished studies that describe the incidence of rotavirus diarrhea in the community and the prevalence of rotavirus infection among patients hospitalized with diarrhea. This information was then integrated with data from the National Diarrheal Disease Control Program in Peru in order to estimate the proportion of diarrheal morbidity and mortality attributable to rotavirus for 1996, the most recent year in which data were available from all sources for that year's birth cohort, which included approximately 600000 infants. The resulting information was combined with recently conducted national estimates of the cost of medical services in order to determine the total cost of rotavirus diarrhea in Peru and the price at which a vaccine would be cost-saving for the national immunization program. We could not find adequate economic information to assess the indirect or societal costs of the disease in order to estimate the cost-effectiveness of an immunization program. Therefore, this analysis represents a preliminary approach toward both the determination of the disease burden and analyses of costeffectiveness.

\section{MATERIALS AND METHODS}

\section{Community Studies}

We identified six longitudinal studies that examined the incidence of rotavirus diarrhea in Peruvian children. Five of the studies (8-12) were conducted in a poor urban area of Lima, which is located on Peru's Pacific coast and is the country's capital. The sixth study was conducted in the city of Huaraz, which is in Peru's interior highland (Lanata CF et al., unpublished, 1987). Three of these studies were field trials of candidate rotavirus vaccines $(9,11,12)$; using these studies, we analyzed the incidence of rotavirus diarrhea among the children in the placebo groups. Some epidemiologists have argued that disease incidence may not be properly assessed from placebo groups in intervention studies, so we compared the incidences within these groups with those in the longitudinal studies to look for possible bias. In all of the studies, we selected for our analysis the data on children under 2 years old. The incidence of rotavirus disease in each site was calculated as the percentage of diarrheal episodes found to be associated with rotavirus multiplied by the episodes of any diarrhea/child-year.

\section{Health facility studies}

We identified 13 studies that reported the proportion of diarrheal episodes due to rotavirus among children seen at three hospitals and one outpatient clinic over a period of 1 year or more. Of these 13 studies, 9 of them were published (13-21) and 4 of them were unpublished ( 3 studies by Chea $\mathrm{E}$ et al., 1992, 1994, 1996; 1 study by Stephensen C et al., 1991, which provided both inpatient and outpatient data). The age ranges of these studies varied, and we had no access to original data that would have enabled us to adjust for the differences. Eight of the 13 studies were conducted among children under 2 years of age, two of them focused on children 3-36 months old, and the remaining three included children less than 5 years old. Despite the age differences among the study groups, we found that the means and medians of the ratio of rotavirus episodes fell into approximately the same range, as we will describe later in the Results section of this paper. Given this fact and the limited data available, we decided to combine all 13 studies in our calculations to create a rough estimate of rotavirus prevalence among children less than 5 years old.

\section{National estimates of the incidence of diarrhea and rotavirus diarrhea}

Community surveys. We obtained an alternate estimate of the incidence of childhood diarrhea from Peru's 1996 national Survey of Population and Family Health (SPFH-96) (22). That survey provided data on the percentage of children less than 5 years of age who reported an episode of nonbloody diarrhea in the 2 weeks prior to 
the survey. We extrapolated from this incidence rate to determine the number of cases of diarrhea experienced by children throughout the country in 1996. We then estimated the proportion of these community-based diarrheal cases caused by rotavirus by applying the rate of rotavirus disease determined from our review of community studies.

Surveys of health care delivery. Peru's National Diarrheal Disease Control Program provided information regarding the number of diarrheal cases seen at health care facilities in the country. These data included the number of patients less than 5 years old with acute watery diarrhea who were reported as receiving treatment at any $\mathrm{MOH}$ hospital or clinic. We used this information to calculate the rate of diarrhea in health facilities per 1000 children for 1996.

The data from the National Diarrheal Disease Control Program combined cases seen at outpatient clinics with cases that required hospitalization. To estimate the respective number of cases seen in these separate settings, we used unpublished information from two sources.

One source (Condor $\mathrm{M}$ et al., personal communication, 1998) provided information on the district of San Juan de Lurigancho in Lima and the proportions there of all diarrhea cases among children less than 5 years old seen at the $\mathrm{MOH}$ facilities requiring hospitalization for moderate to severe dehydration (according to World Health Organization criteria). Those proportions were $18.0 \%$ in $1995,28.0 \%$ in 1996, and 10.1\% in 1997 (mean, 21.8\%).

The second source (Salazar-Lindo E et al., personal communication, 1998) concerned the proportions of diarrhea episodes with moderate to severe dehydration in children under 5 years of age seen at the emergency room clinic in the Cayetano Heredia Hospital in Lima. Those proportions were $23.3 \%$ in March 1998, 24.0\% in April 1998, and 18.7\% in May 1998 (mean, 22.3\%) (Salazar-Lindo E et al., personal communication, 1998).
Based on the data from these two sources, we estimated that $78 \%$ of diarrheal cases seen by $\mathrm{MOH}$ facilities were treated as outpatients and $22 \%$ required hospitalization. As above, we then estimated the proportion of these hospital-based diarrheal cases caused by rotavirus by applying the rate of rotavirus disease determined from our review of health facility studies.

Mortality. Each year the MOH compiles a report on mortality that includes information on the number of diarrhea-associated deaths among children less than 5 years of age. However, this information includes only the deaths that occurred in $\mathrm{MOH}$ facilities. To create a more accurate view of diarrheal mortality, we referred to the data published in the State of the World's Children 1998, which reported all deaths of children less than 5 years of age (7). We estimated that $20 \%-25 \%$ of the 36000 deaths in Peru were caused by diarrhea and, conservatively, that $20 \%$ of these diarrhea-caused deaths could be associated with rotavirus. The first of those proportions was based on a review of diarrheal mortality conducted by Bern et al. (23), and the second on a review by de Zoysa et al. (24). The $20 \%$ rotavirus proportion is particularly conservative when compared to the $32 \%$ figure that we found among hospitalized Peruvian children, as we will explain in the Results section of this paper.

\section{Disease cost estimates}

We could find no surveys conducted in Peru that examined indirect or societal costs to families of a child with diarrhea, such as the value of paid work time lost by the family members caring for the ill child. The cost data for outpatients and inpatients were derived from a 1994 multihospital study conducted by Proyecto 2000, a project of the Peruvian MOH and the United States Agency for International Development (USAID). The Proyecto 2000 study (25) generated cost estimates based on expendi- tures during the study period for 10 hospitals and 40 health centers or sanitary posts located throughout Peru. These costs varied by the number of patients seen and the location (urban vs. rural) of the clinic. Diarrhea-associated cost estimates included the allocated proportions of salaries, services, supplies, equipment (depreciated over 10 years), infrastructure (estimated rental market value), and administrative costs (salaries and general services such as nutritional support, laundry, pharmacy, and maintenance).

The Proyecto 2000 study found that the mean cost of an ambulatory visit for diarrhea ranged from US\$ 7.49 to US\$ 16.56 and that the mean cost to hospitalize a child ranged from US\$ 44.69 to US\$ 62.33 per day. Since we could find no data on the cost of a diarrheal death, we estimated this amount to be equivalent to the cost of one hospital day, since most fatalities occur on the day of admission. Length of stay of the 30400 children who were hospitalized was estimated according to information from two diarrhea treatment units in Lima. In these two units, $90 \%$ of patients were hospitalized less than 24 hours, $8 \%$ stayed 24 48 hours, and $2 \%$ remained for more than 48 hours (Figueroa D and Salazar $\mathrm{E}$, personal communications, 1998). Once we determined the number of events (outpatient visits, inpatient hospital days, and deaths), we were able to calculate the total cost of rotavirus diarrhea to Peru by multiplying the number of events by the estimated cost of the service. Finally, we estimated the rotavirus-related cost per child under age 5 based on the risk of experiencing each of the three events (an outpatient visit, hospitalization, or death).

\section{Immunization cost estimates}

The cost to administer a rotavirus vaccine orally (excluding the vaccine price) was estimated based on cost figures provided by the National Immunization Program of the $\mathrm{MOH}$ for a campaign in which only oral polio vaccine $(\mathrm{OPV})$ was administered. 
These costs amounted to US\$ 0.61 per dose for an immunization conducted at a health facility, US\$ 0.70 per dose for those performed in outreach actions in urban areas, and US\$2.44 per dose in outreach actions in rural areas. The Immunization Program estimates that $30 \%$ of OPV dosages are given at health facilities, $50 \%$ in outreach actions in urban areas, and 20\% in rural areas (Strul M, unpublished information, 1998). These costs included only direct costs due to transportation of OPV vaccine and personnel, logistical support, cold chain consumables, and other similar costs, and did not include salaries of staff, the fixed cost of vehicles or equipment, and administrative costs or treatment of adverse events. Since the rotavirus vaccine will most likely be used in combination with oral polio and the diphtheria-pertussistetanus (DPT) vaccine, one-third of the total delivery cost was allocated to the rotavirus vaccine. These costs were applied to Peru's estimated annual birth cohort of 600000 .

\section{Vaccine price estimates}

We estimated the current medical costs (both inpatient and outpatient) for rotavirus diarrhea using $\mathrm{MOH}$ data for diarrhea treatment among children less than 5 years of age. From this total, we subtracted the potential cost of delivering the rotavirus vaccine to Peru's annual birth cohort. The difference represents the portion of the existing budget that would be available to purchase rotavirus vaccine and treat diseases among those children who remained unprotected. This difference also indicated a break-even point for the vaccine to be cost-saving. However, the cost of the vaccine could be higher if indirect or societal costs were included in the calculation of costeffectiveness, or if parents were willing to pay for at least some part of the immunization costs for their children.

\section{RESULTS}

\section{Disease burden}

We reviewed both published and unpublished studies in order to assess the rotavirus diarrhea disease burden in Peru. Six available longitudinal studies provided estimates for the incidence of rotavirus diarrhea based on more than 1000 child-years of observation over a 10-year period (Table 1).
The Lima results suggest that the incidence of diarrheal disease has declined slightly over time, from 9.8 episodes/child year in 1984 to 8.3 episodes in 1991 (median of 9.0), and that rotavirus was detected in $3.4 \%$ of these episodes (range, 2.6\%-4.2\%). Extrapolating these results to the rest of Peru, it appears that a median of $30.9 \%$ (range, 27.6\%-37.8\%) of Peruvian children have a rotavirus diarrhea episode each year for the first 2 years of life. No difference in incidence was noted among children who were involved in the intervention studies as compared to those who were not. However, the incidence of rotavirus diarrhea reported in the mountainous region of Huaraz, based on a single study conducted from 1986 to 1987, found that only $19.7 \%$ of children experienced such an episode (Lanata et al., unpublished, 1987).

Thirteen studies addressed the etiology of disease among children hospitalized for diarrhea (Table 2). One other study, conducted among outpatients, reported that rotavirus was the primary etiologic agent in 19\% of those children with diarrhea. The 13 inpatient studies were conducted between January 1982 and February 1997, in three hospitals in Lima. These studies

TABLE 1. Review of community studies: incidence of rotavirus (RV) diarrhea among Peruvian children $<2$ years of age

\begin{tabular}{|c|c|c|c|c|c|c|c|}
\hline \multirow[b]{2}{*}{ Study } & \multirow[b]{2}{*}{ Dates of study } & \multirow[b]{2}{*}{ Child-years } & \multirow[b]{2}{*}{$\begin{array}{l}\text { Episodes of } \\
\text { diarrhea/ } \\
\text { child-year }\end{array}$} & \multicolumn{4}{|c|}{ Rotavirus diarrhea } \\
\hline & & & & No. screened & No. positive & $\%$ positive & $\begin{array}{c}\text { Episodes of } \\
\text { RV diarrhea/ } \\
100 \text { child-years }^{a}\end{array}$ \\
\hline \multicolumn{8}{|l|}{ Lima } \\
\hline Black et al., 1989b & $7 / 82-6 / 84$ & 133 & 9.8 & 952 & 30 & 3.2 & 30.9 \\
\hline Lanata et al., $1989^{c}$ & $1 / 85-7 / 86$ & 127 & 10.6 & 1343 & 35 & 2.6 & 27.6 \\
\hline Lanata et al., $1992^{d}$ & $1 / 85-3 / 87$ & 434 & 9.0 & 3143 & 108 & 3.4 & 30.9 \\
\hline Lanata et al., $1996^{c}$ & $8 / 87-10 / 90$ & 339 & 8.9 & 1931 & 82 & 4.2 & 37.8 \\
\hline Lanata et al., $1996^{c}$ & $10 / 88-8 / 91$ & 386 & 8.3 & 2115 & 87 & 4.1 & 34.1 \\
\hline Total/median ${ }^{e}$ & & 1419 & 9.0 & 9483 & 342 & 3.4 & 30.9 \\
\hline \multicolumn{8}{|l|}{ Huaraz } \\
\hline Lanata et al., unpubl., 1987 & $9 / 86-8 / 87$ & 199 & 7.0 & 1385 & 39 & 2.8 & 19.7 \\
\hline
\end{tabular}


TABLE 2. Review of inpatient and outpatient studies: prevalence of rotavirus (RV) among children $<5$ years of age seen for diarrhea in Lima, Perua $^{\mathrm{a}}$

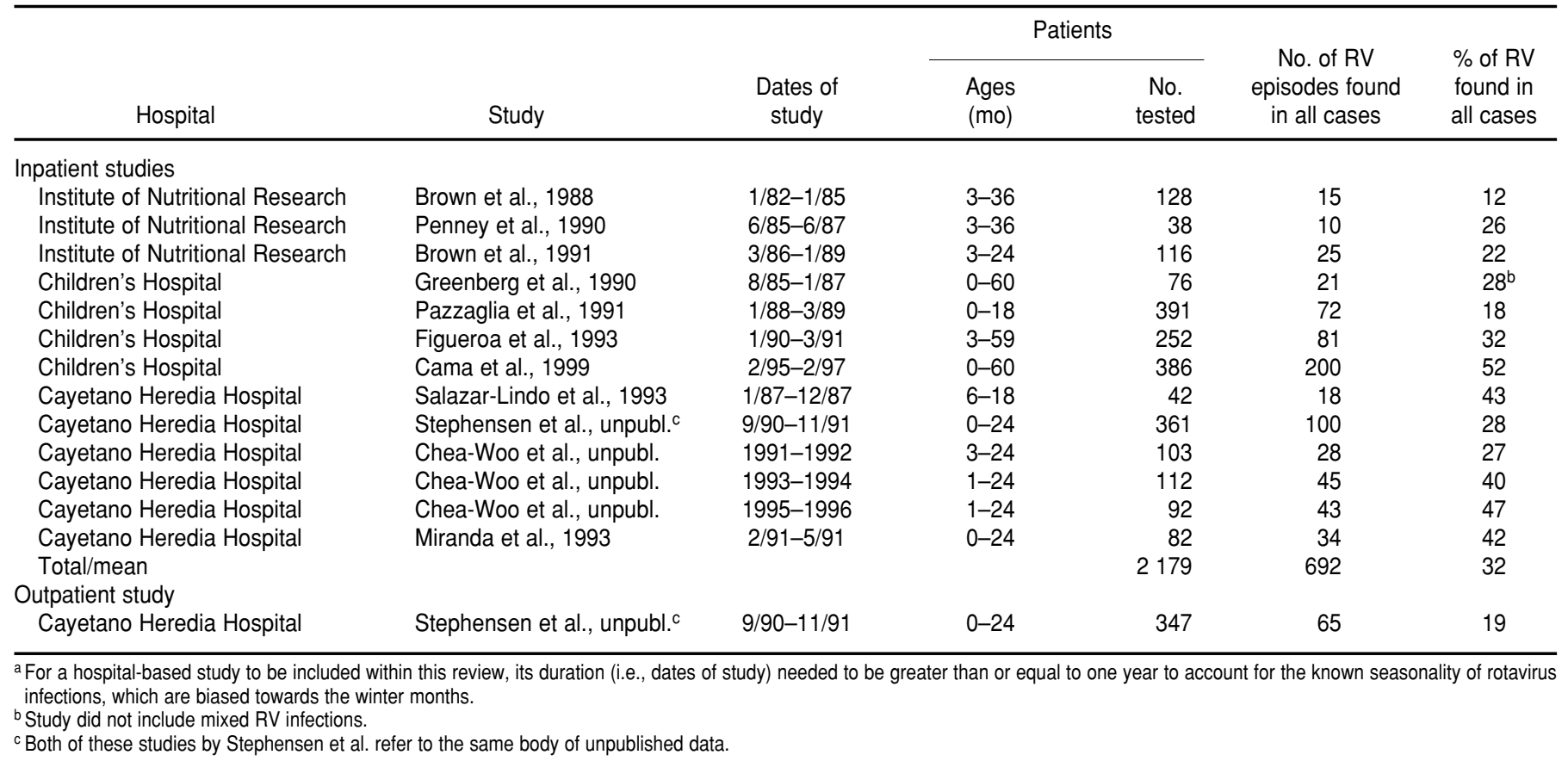

included observations on more than 2000 children, all under 5 years of age. Among patients hospitalized for diarrhea, a mean of $32 \%$ (range, $12 \%-52 \%$ ) had rotavirus detected as the etiologic agent. As noted in the Methods section of this paper, this mean figure was similar to the median (28\%) and was not altered when adjusted for the different sizes of populations studied or for changes in the age group under investigation (i.e., $0-2$ years or $0-5$ years). The prevalence of rotavirus diarrhea varied by hospital, with the Institute of Nutritional Research reporting noticeably lower figures $(12 \%-26 \%)$ than either the Children's Hospital (18\%$52 \%$ ) or the Cayetano Heredia Hospital $(27 \%-47 \%)$, both of which handle a substantial number of referrals of dehydrated diarrheal cases. The prevalence of rotavirus also varied according to the inpatient study size, accounting for a greater amount of disease in the 5 studies with fewer than 100 patients than in the 8 larger studies.

Results from the SPFH-96 survey indicated that diarrhea is extremely common among the 2.9 million Peru- vian children less than 5 years old (Table 3). Cumulatively, they experience 3.9 episodes per child-year, or 11.3 million episodes per year. This rate is significantly lower than the 9.0 episodes per child-year noted by the active surveillance of diarrhea among children less than 2 years old in the longitudinal studies reviewed for this paper, a difference that may be partially reconciled by the differences in the age groups studied.

Health facility visits due to diarrheal disease are also common in Peru (Table 3). According to the 1996 surveillance data of the National Diarrheal Disease Control Program, a total of 431506 children visited MOH clinics and hospitals for diarrhea-related reasons. Of these patients, we determined that $78 \%$ were outpatients and $22 \%$ were inpatients. Consequently, the $\mathrm{MOH}$ treated approximately 336000 of the 11.3 million cases as outpatients and another 95000 in the hospital. Mortality associated with diarrhea among children less than 5 years old was approximately 8000 children per year. Applying these figures to the birth cohort of 600000 infants, we estimate that by the age of 5 years, 1 in 1.8 children would visit an outpatient department, 1 in 6.3 would be hospitalized, and 1 in 75 would die of diarrhea.

From these figures on childhood diarrhea, we estimated the potential role attributable to rotavirus (Table 3 ). Rotavirus was associated with $3.4 \%$ of all diarrheal episodes in the community, $19 \%$ of episodes leading to an outpatient visit, $32 \%$ of episodes leading to hospitalization, and $20 \%$ of fatal cases. Cumulatively, by age 5 years, one child in 1.6 will have an episode of rotavirus diarrhea, 1 in 9.4 will need outpatient care, 1 in 19.7 will be hospitalized, and about 1 in 375 will die from the disease.

The medical costs attributable to rotavirus diarrhea were estimated from the perspective of the health care system and the cumulative risk for a child up to age 5 (Table 4). The medical cost of rotavirus disease was obtained by multiplying the number of rotavirus diarrhea events by the cost per event, taking into account the average length of stay of an inpatient hospitalization, 
TABLE 3. Estimated burden of all diarrhea and of rotavirus-associated diarrhea among 2.9 million Peruvian children $<5$ years of age (i.e., a birth cohort of 600000 children/year)

\begin{tabular}{|c|c|c|c|c|c|c|c|}
\hline & \multicolumn{3}{|c|}{ All diarrhea episodes } & \multicolumn{4}{|c|}{ Rotavirus (RV) diarrhea episodes } \\
\hline & $\begin{array}{c}\text { Annual } \\
\text { total } \\
\text { no. }\end{array}$ & $\begin{array}{l}\text { Incidence risk } \\
\text { per } 100 \\
\text { child-years }\end{array}$ & $\begin{array}{l}\text { Cumulative } \\
\text { risk/child } \\
\text { by age } 5\end{array}$ & $\begin{array}{l}\% \text { of all } \\
\text { diarrhea } \\
\text { episodes }\end{array}$ & $\begin{array}{l}\text { Annual } \\
\text { total } \\
\text { RV no. }\end{array}$ & $\begin{array}{l}\text { Incidence risk } \\
\text { per } 100 \\
\text { child-years }\end{array}$ & $\begin{array}{l}\text { Cumulative } \\
\text { risk/child } \\
\text { by age } 5\end{array}$ \\
\hline Total episodes & 11300000 & 390 & 18.9 episodes in 1 child & 3.4 & 384000 & 13 & 1 episode in 1.6 children \\
\hline Outpatient visits & 336000 & 12 & 1 in 1.8 children & 19 & 64000 & 5.2 & 1 in 9.4 children \\
\hline Hospital admissions & 95000 & 3.3 & 1 in 6.3 children & 32 & 30000 & 2.1 & 1 in 19.7 children \\
\hline
\end{tabular}

TABLE 4. Estimated medical costs (US\$) of rotavirus diarrhea for the health care system of Peru, annually and per-child by age 5

\begin{tabular}{lcccccc}
\hline Event & $\begin{array}{c}\text { Estimated } \\
\$ \text { cost/event }\end{array}$ & $\begin{array}{c}\text { Annual no. } \\
\text { of events }\end{array}$ & $\begin{array}{c}\text { Estimated total } \\
\text { annual costs }(\$)\end{array}$ & & \multicolumn{2}{c}{ Per child by age 5 } \\
\hline Outpatient visit & 12.03 & 63930 & 769000 & & $\$$ cost $^{\mathrm{a}}$ \\
\hline Hospitalizations & $59.93^{\mathrm{b}}$ & 30400 & 1822000 & 0.11 & 1.32 \\
Death & 53.51 & 1600 & 86000 & 0.003 & 0.16 \\
$\quad$ Total cost/mean & & & 2600000 & & NA $^{\mathrm{c}}$ & 4.48 \\
\hline
\end{tabular}

a cost $=$ cost/event $\times$ risk/child by age 5 years.

b Estimated $\$$ cost/hospitalization was calculated using the estimates that each hospital day cost $\$ 53.51$ and $90 \%$ of children remained for 1 day, $8 \%$ of children remained for 2 days, and $2 \%$ of children remained for 3 days.

${ }^{c} \mathrm{NA}=$ not applicable.

1.12 days. We estimated that the Peruvian $\mathrm{MOH}$ spends over US\$2.6 million each year to treat rotavirus-related disease among children less than 5 years old. Of these factors, inpatient hospitalization costs account for US\$ 1.8 million, or some $70 \%$ of these costs. The average per-child cost of rotavirus disease by age 5 was estimated at US\$ 4.48. This figure is the sum of the cost of each event (outpatient visit, hospitalization, death) multiplied by the child's risk of experiencing each event.

The cost of delivering three doses of an oral rotavirus vaccine was estimated according to current $\mathrm{MOH}$ figures for the delivery of other vaccines. We used the actual delivery cost of a single dose of oral polio vaccine (OPV) to the birth cohort of 600000 infants in 1996, but we took into account the $81 \%$ coverage for the third of the three doses of diphtheria-pertussistetanus (DPT) vaccine. Rotavirus vaccine would be most efficiently added to the existing Expanded Program of Immunization (EPI) schedule if it could be given with other three-dose vaccinations, such as DPT and OPV. Thus, a rotavirus vaccine budget would be expected to assume only one-third of the total US\$ 1443000 delivery costs, or some US\$ 481000 . Subtracting this delivery cost from the current US\$ 2.6 million annually allocated to treating rotavirus diarrhea leaves a theoretical maximum of US\$ 2.1 million to purchase the vaccine and treat remaining cases of rotavirus diarrhea. If the Peruvian $\mathrm{MOH}$ wanted to vaccinate its 600 000-infant birth cohort within this budget, it could not afford to spend any more than about US $\$ 3.50$ per regimen per infant. It is important to note that this rough figure was calculated by dividing the existing budget by the birth cohort, and may be as much as two times the amount that the Peruvian $\mathrm{MOH}$ could actually afford to spend on a vaccine regimen.

\section{DISCUSSION}

This review confirms that rotavirus is the most common cause of severe diarrhea in Peruvian children and that it is a target worthy of a future program of prevention through immunization. We estimate that by the age of 5 years more than $63 \%$ of Peruvian children will have experienced an episode of rotavirus diarrhea, 1 in 9.4 will seek care at a clinic, 1 in 19.7 will be hospitalized, and about 1 in 375 will die of their disease. Given these figures and the estimated additional cost of administering rotavirus vaccine along with the other routine childhood immunizations, the cost of a rotavirus vaccine would need to be quite inexpensive for the program to be cost-saving. However, as this study could not include total costs (medical as well as indirect or societal), we could not establish a specific price at which a rotavirus program would be costeffective. Nonetheless, the ability to prevent a single death by vaccinating 375 children compares favorably to the benefits of other childhood immunizations.

There are alternative approaches to decreasing the impact of rotavirus diarrhea. One of these is to improve access to early treatment with oral rehydration, a program that has been the mainstay of the diarrheal disease control effort in Peru for two decades. These efforts, however, have not noticeably changed the incidence of rotavirus diarrhea, which remains the main cause of diarrhea hospitalizations.

Recent studies have examined the potential cost-effectiveness of rotavirus 
immunization programs in Australia, Finland, and the United States as well as the rotavirus disease burden in Argentina, a country that shares some characteristics with both developed and developing countries (26-29). In comparison to those four countries, Peru has less health care infrastructure and less money to spend on a vaccination program. The average cost for an unvaccinated patient with severe rotavirus diarrhea to visit an outpatient facility would be US\$ 132 in the United States, US\$ 30 in Argentina, but just US\$ 12 in Peru. For inpatient care, the average cost of hospitalization would be US\$ 2672 in the United States, US\$ 900 in Argentina, but just US\$ 60 in Peru. Nonetheless, hospital care in Peru, as elsewhere, represents the largest health care expense for rotavirus disease.

This study is preliminary and has many limitations. The most important of these is the lack of data on societal or indirect (nonmedical) costs that rotavirus diarrhea places on affected families. Without this data, a true costeffectiveness analysis cannot be performed. At the same time, given the high mortality estimated for rotavirus diarrhea, the real argument for the vaccine in Peru, as in other developing countries, is not based on the marginal economic gain from prevention of mild disease but on the measurable prevention of loss of life among children. We were also limited by the depth of the data that were available to calculate the rotavirus disease burden at each level of concern: community, health facility, and national. Five of the six community studies that we utilized were performed in the same poor community on the outskirts of Lima, and for three of them, we acquired data from the placebo group of vaccine trials. No difference in incidence was noted between placebo recipients and other studies. The hospital-based studies were also restricted to the population of Lima. Therefore, neither our calculation of the incidence of rotavirus in the community nor the prevalence of rotavirus among hospitalized patients with diarrhea reflects the true geographic, climatic, or socioeconomic diversity of Peru. On the national scale, we used the SPFH-96 survey as the framework for our estimates of the incidence of rotavirus diarrhea in the country, but we did not take into account the known seasonality of the virus nor the sampling error of the survey. We also did not have any means of confirming the inclusiveness of the data supplied by the National Diarrheal Disease Control Program.

This review assumes that rotavirus vaccination would occur as a threedose regimen on a regular EPI schedule of 6,10 , and 14 weeks, as is done in the vaccine field trials under ideal conditions. That defined regimen would prevent the largest proportion of rotavirus infections, but it is likely that a proportion of infants would receive the vaccine at older ages. These children would have a greater chance of having a rotavirus diarrheal episode before receiving the vaccine, thus reducing the potential impact of the immunization program. For these reasons, when a new vaccine is licensed, it is important to conduct a large intervention trial in order to evaluate its true impact under field conditions. An important aspect of such a study is to assess the number of deaths averted by the use of the vaccine. Moreover, given the limited budget funds available for the implementation of new vaccines, regimens with fewer than three doses should be tested for efficacy. A one- or two-dose regimen, for example, would lead to a substantial cost savings for the Peruvian $\mathrm{MOH}$.

Implementing a rotavirus vaccine program in Peru would greatly impact the large numbers of patients with severe rotavirus diarrhea seen at $\mathrm{MOH}$ clinics and hospitals. However, a single family would likely not see much individual benefit after vaccinating its child against rotavirus, since the fraction of all diarrheal episodes that is caused by rotavirus is small. Therefore, an important aspect of a rotavirus immunization program will be educating parents on the importance of vaccinat- ing their children even though the impact may not be directly evident.

The preliminary data found in this study are interesting, but they rely extensively on extrapolation because more complete information was not available. Estimates of rotavirus disease burden, mortality, and costs need to be updated and expanded to include the entire country. Once these data are collected, the risks of intussusception associated with the WyethLederle Rotashield $^{\circledR}$ vaccine may prove to be of less importance. Other new vaccine formulations are forthcoming. These will need demonstration studies to answer important questions concerning their efficacy and cost. For example, will a new vaccine work in settings where children have very high rates of diarrhea? Will it be efficacious among children in Peru? Will two doses or even just one dose of such a vaccine also prove to be effective? Each of these issues will directly affect the cost of a mass immunization program, as would more exact population and cost estimates from the $\mathrm{MOH}$ regarding immunization. Opportunities to examine these questions should occur over the next 3 to 5 years as the next generation of rotavirus vaccines is licensed for use in children.

Acknowledgments. We thank Elsa Chea, Dante Figueroa, and Charles Stephensen for sharing their unpublished information; Midori de Habich at Proyecto 2000 for information on cost-benefit studies and advice on analysis; Myriam Strul and Luis Vergara at the Peru Ministry of Health and Diarrheal Disease Control Program for providing us with official figures and discussing our paper; John O'Connor, of the Centers for Disease Control and Prevention, for editorial assistance; and Robert Black and Robert Gilman for providing support and comments. Co-author Peter Ehrenkranz was supported by student research grants from Solvay Pharmaceuticals and from the Emory University School of Medicine. 


\section{REFERENCES}

1. Miller MA, McCann L. Policy analysis of the use of hepatitis B, Haemophilus influenzae type B, Streptococcus pneumoniae-conjugate, and rotavirus vaccines in national immunization schedules. Health Econ 2000;9(1):19-35.

2. American Academy of Pediatrics. Prevention of rotavirus disease: guidelines for use of rotavirus vaccine. Pediatrics 1998;102(6): 1483-1491.

3. United States of America, Centers for Disease Control and Prevention. Rotavirus vaccine for the prevention of rotavirus gastroenteritis among children. Recommendations of the Advisory Committee on Immunization Practices (ACIP). MMWR 1999;48(No.RR-2):1-20.

4. Kramarz P, France EK, Destefano F, Black SB, Shinefield H, Ward JI, et al. Population-based study of rotavirus vaccination and intussusception. Pediatr Infect Dis J 2001;20:410-416.

5. Weijer $\mathrm{C}$. The future of research into rotavirus vaccine. BMJ 2000;321(7260):525-526.

6. United States of America, Centers for Disease Control and Prevention; World Health Organization; Children's Vaccine Initiative. Report. Proceedings of the Consensus Workshop: Rotavirus Vaccines for the Immunization of Children in Developing Countries, Geneva, 9-10 January, 1997.

7. United Nations Children's Fund. State of the world's children 1998. New York: UNICEF, Oxford University Press; 1998.

8. Black RE, Lopez de Romana G, Brown KH, Bravo N, Grados Bazalar O, Kanashiro HC. Incidence and etiology of infantile diarrhea and major routes of transmission in Huascar, Peru. Am J Epidemiol 1989;129(4):785-799.

9. Lanata CF, Black RE, del Aguila R, Verastegui $\mathrm{H}$, Gerna G, Flores J, et al. Protection of Peruvian children against rotavirus diarrhea of specific serotypes by one, two, or three doses of the RIT 4237 attenuated bovine rotavirus vaccine. J Infect Dis 1989;159(3):452-459.

10. Lanata CF, Black RE, Maurtua D, Gil A, Gabilondo A, Yi A, et al. Etiologic agents in acute vs. persistent diarrhea in children under 3 years of age in peri-urban Lima, Peru. Acta Paediatr Suppl 1992;381:32-38.

11. Lanata CF, Black RE, Flores J, Lazo F, Butron B, Linares $\mathrm{A}$, et al. Immunogenicity, safety and protective efficacy of one dose of the rhesus rotavirus vaccine and serotype 1 and 2 humanrhesus rotavirus reassortants in children from Lima, Peru. Vaccine 1996;14:237-243.

12. Lanata $C F$, Midthun $K$, Black RE, Butron $B$, Huapaya A, Penny ME, et al. Safety, immunogenicity, and protective efficacy of one and three doses of the tetravalent rhesus rotavirus vaccine in infants in Lima, Peru. J Infect Dis 1996;174(2):268-275.

13. Brown KH, Perez F, Gastanaduy AS. Clinical trial of modified whole milk, lactosehydrolyzed whole milk, or cereal-milk mixtures for the dietary management of acute childhood diarrhea. J Pediatr Gastroenterol Nutr 1991;12(3):340-350.

14. Penny ME, Paredes $P$, Brown KH, Laughan $B$, Smith $\mathrm{H}$. Lack of a role of the duodenal microflora in pathogenesis of persistent diarrhea and diarrhea-related malabsorption in Peruvian children. Ped Infect Dis J 1990;9:479-487.

15. Greenberg BL, Sack RB, Salazar-Lindo E, Budge E, Gutierrez M, Campos M, et al. Measles-associated diarrhea in hospitalized children in Lima, Peru: pathogenic agents and impact on growth. J Infect Dis 1991;163: 495-502.

16. Pazzaglia G, Sack RB, Salazar E, Yi A, Chea E, Leon-Barua $\mathrm{R}$, et al. High frequency of coinfecting enteropathogens in Aeromonas-associated diarrhea of hospitalized Peruvian infants. J Clin Microbiol 1991;29:1151-1156.

17. Figueroa-Quintanilla D, Salazar-Lindo E, Sack RB, Leon-Barua R, Sarabia-Arce S, CamposSanchez M, et al. A controlled trial of bismuth subsalicylate in infants with acute watery diarrheal disease. N Engl J Med 1993;328: 1653-1658.

18. Cama RI, Parashar UD, Taylor DN, Hickey T, Figueroa D, Ortega YR, et al. Enteropathogens and other factors associated with severe disease in children with acute watery diarrhea in Lima, Peru. J Infect Dis 1999;179:1139-1144.

19. Salazar-Lindo E, Salazar M, Alvarez JO. Association of diarrhea and low serum retinol in Peruvian children. Am J Clin Nutr 1993;58: 110-113.

20. Barnes GL, Lund JS, Adams L, Mora A Mitchell SV, Caples A, et al. Phase 1 trial of a candidate rotavirus vaccine (RV3) derived from a human neonate. J Paediatr Child Health 1997:33:300-304.

21. Miranda-Langschwager P, Salazar-Lindo E, Chea-Woo E, Santisteban-Ponce J. Desarrollo de una escala clínica para el diagnóstico de cólera en lactantes con diarrea acuosa. Bol Med Hosp Infant Mex 1993; 50(11):781-788.

22. Instituto Nacional de Estadística e Informática and Macro International Inc. Perú. Encuesta demográfica y de salud familiar 1996. Lima, Perú: Instituto Nacional de Estadística e Informática; 1997.

23. Bern C, Martines I, de Zoysa I, Glass RI. The magnitude of the global problem of diarrhoeal disease: a ten-year update. Bull World Health Organ 1992;70(6):705-714.

24. de Zoysa I, Feachem RG. Interventions for the control of diarrhoeal disease among young children: rotavirus and cholera immunization. Bull World Health Organ 1985;63(3):569-583.

25. Perú, Ministerio de Salud. Seminario Modernización del Sistema de Financiamiento de Salud - 1997: análisis de costos de los servicios de salud. Lima: MINSA; 1997. Proyecto 2000.

26. Ferson MJ. Hospitalizations for rotavirus gastroenteritis among children under five years of age in New South Wales. Med J Aust 1996; 164(5):273-276

27. Takala A, Koskenniemi E, Joensuu J, Mäkelä $\mathrm{M}$, Vesikari T. Economic evaluation of rotavirus vaccinations in Finland; randomized, double-blind, placebo controlled trial of tetravalent rhesus rotavirus vaccine (RRV-TV) Clin Infect Dis 1998;27:272-282.

28. Tucker AW, Haddix AC, Bresee JS, Holman RC, Parashar UD, Glass RI. Cost-effectiveness analysis of a rotavirus immunization program for the United States. JAMA 1998;279(17): 1371-1376.

29. Gomez JA, Nates S, De Castagnaro NR, Espul C, Borsa A, Glass RI. Anticipating rotavirus vaccines: review of epidemiologic studies or rotavirus diarrhea in Argentina. Rev Panam Salud Publica 1998;3(2):69-78.

Manuscript received 23 March 2001. Revised version accepted for publication on 2 August 2001. 
RESUMEN Objetivos. Evaluar la carga de morbilidad de la diarrea por rotavirus en Perú, la necesidad de una vacuna y el ahorro que esta podría proporcionar en este país.

Carga de morbilidad de la diarrea por rotavirus en Perú: la necesidad de una vacuna y su potencial de ahorro

Métodos. Para evaluar la carga de morbilidad de la diarrea por rotavirus en Perú, se revisaron los estudios publicados y no publicados sobre los rotavirus como causa de diarrea en niños. Las tasas de detección de rotavirus en estos estudios se combinaron con las tasas de incidencia de diarrea procedentes de varias encuestas nacionales, con el fin de estimar tanto la carga de morbilidad de la diarrea por rotavirus como sus costos médicos.

Resultados. Los rotavirus son una importante causa de morbilidad y mortalidad en los niños peruanos. Se estima que, en sus primeros 5 años de vida, 1 de cada 1,6 niños sufre un episodio de diarrea por rotavirus, que 1 de cada 9,4 busca atención médica, que 1 de cada 19,7 necesita ser hospitalizado y que 1 de cada 375 muere por esta causa. Cada año, esto representa aproximadamente 384000 casos, 64000 consultas, 30000 hospitalizaciones y 1600 muertes. El costo anual únicamente de la atención médica de estos niños es de aproximadamente 2,6 millones de dólares estadounidenses, sin tener en cuenta los costos indirectos o sociales de la enfermedad y las muertes.

Conclusiones. La vacunación contra los rotavirus permite albergar la esperanza de reducir la morbilidad y mortalidad de la diarrea en Perú, pero el régimen de vacunación debería ser relativamente barato (unos pocos dólares por niño). En el futuro, los análisis de costo-efectividad deberían investigar los costos totales (tanto los médicos como los indirectos o sociales) de la diarrea por rotavirus, y las vacunas que se aprueben deberían ser probadas en lo que se refiere tanto a su capacidad para evitar las muertes como a su eficacia con menos de tres dosis. Estos tres factores podrían incrementar el ahorro proporcionado por la vacuna contra los rotavirus.

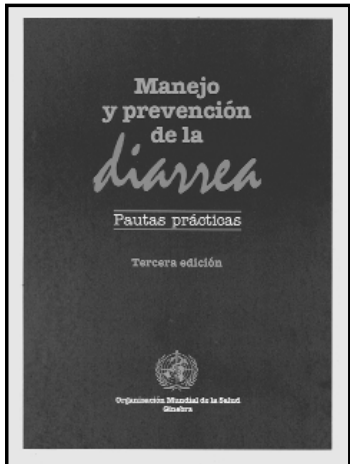

\section{Manejo y prevención de la diarrea. Pautas prácticas, $3 .^{a}$ ed.}

Esta tercera edición revisada constituye una guía práctica para enseñar a los agentes de salud a determinar si una persona padece diarrea y deshidratación, a tratar eficazmente estos casos y motivar a los miembros de la comunidad a adoptar prácticas preventivas. Aplicando criterios didácticos, el manual utiliza un lenguaje sencillo, apoyado por abundantes diagramas, cuadros, listas de comprobación e ilustraciones.

$1994 \cdot 50$ pp. • ISBN 9243544543 • Código: WHO 9

Precios: US\$ 11.00 / US\$ 9.00 en América Latina y el Caribe

http://publications.paho.org•Fax: (301) 206-9789•Correo electrónico:paho@pmds.com 